\title{
Innovative Food Systems Teaching and Learning: overcoming disciplinary and teaching silos to fix the food system
}

\author{
Ajates Gonzalez, Raquel ${ }^{\mathrm{a}}$ \\ ${ }^{a}$ DJCAD, University of Dundee, Scotland and City University of London, England
}

\begin{abstract}
While inter-university and interdisciplinary research projects are very common in Higher Education (HE), inter-university and interdisciplinary teaching programmes are still very rare. This paper reflects on the first year of the Innovative Food Systems Teaching and Learning (IFSTAL) programme. IFSTAL is a three-year project funded by the Higher Education Funding Council for England (HEFCE) with the aim of bringing together postgraduate students from very different programmes to learn about food and farming beyond their own disciplines. IFSTAL creates learning environments and activities that encourage students to think systemically about the transdisciplinary challenges facing the food system. IFSTAL combines both face to face events and an inter-university virtual learning environment (VLE) that was created from scratch for this project. At the end of its first year, a survey was carried out to evaluate the programme and inform the structure for year two (Y2). Survey data revealed students preferred interacting at face to face events over the shared VLE. The programme for Y2 was re-designed to incorporate more flipped classroom features with an andragogy-based approach.
\end{abstract}

Keywords: inter-university; flipped classroom; interdisciplinary teaching; virtual learning environment; postgraduate. 


\section{Introduction: Background information and the structure of the original IFSTAL programme}

IFSTAL is a three-year HEFCE-funded programme across seven English HE institutions to foster interdisciplinary opportunities amongst postgraduate students studying food-related degrees. The consortium started running in September 2015 and is led by Oxford University. The other members are City University of London, Reading University, Warwick University and the Leverhulme Centre for Integrative Research on Agriculture and Health (LCIRAH) - itself a consortium of three institutions: the London School of Hygiene and Tropical Medicine (LSHTM), the School of Oriental and African Studies (SOAS) and the Royal Veterinary College (RVC).

IFSTAL has been designed to offer participants a new holistic framework to think about the food system. This free and voluntary programme is open to any postgraduate students from any subject (both Masters and $\mathrm{PhD}$ ) at the seven participating institutions. Inter-university research projects are common in HE in United Kingdom, but not so inter-university teaching across programmes and disciplines, which is what makes IFSTAL unique. IFSTAL recognises that the complex challenges facing the food system in the XXI century, such as climate change, food poverty, loss of biodiversity and soil, water risks, diet-related diseases, etc., are not disciplinary challenges, but crosscutting ones that require a wide range of disciplines to unpack them, and more importantly, tackle them. IFSTAL introduces students to system thinking approaches to encourage them to think beyond the methods and problem-understanding perspectives of their own disciplines; the programme also fosters interactions between participants and workplace partners both at events and through a diverse range of internships. The objective is to allow students to consider real life challenges they might encounter in their research and workplaces (Ajates Gonzalez and Wells, 2016).

Designing a voluntary programme for such a diverse cohort composed of students at different levels of their postgraduate education (master and $\mathrm{PhD}$ ), from a wide range of disciplines and potentially joining at any time of the academic year was a complex challenge. The approach taken was based on a combination of teaching theories aligned with the use of learning technologies as a way of overcoming the barriers that running a programme across seven different HEs entails. The programme offers students different levels of engagement through a diversity of channels: face to face events of varying lengths and formats (short sessions, lectures, away days and an annual summer school), and online (live-streamed events, VLE, social media channels and e-newsletters), as well as dissertation placements and post-graduation internships. This blended learning approach was adopted to provide a variety of options to a large and diverse IFSTAL cohort and meet different learning styles, content preference and time availability. A blended learning model 
was considered appropriate, as it has been used before to promote interdisciplinary teaching and learning within higher education contexts (Cooner, 2011).

A variety of collaborating platforms and learning technologies are part of the day to day running of IFSTAL for both the team and the students who are based in different cities and distant sites. Interaction across the IFSTAL partners is possible thanks to the ongoing collaboration of a dedicated team of educational technologists and education coordinators who created a brand new Virtual Learning Environment (VLE) shared across all seven institutions. Using Moodle as the underlying platform, the IFSTAL VLE supports fora, teaching materials and quizzes amongst other functionalities such as live chat rooms. Students interested in joining IFSTAL can self-enrol through their institutional VLE. When they enter the VLE, they are counted as having joined the programme. Interested members of staff across the partner institutions also have access to the VLE. Year one of the project implemented the design included in the original proposal to HEFCE based on a core series of eight lectures webcast live across each of the institutions and also live-streamed to facilitate participation to distant students based abroad or unable to attend in person. The live-streaming aspect was a learning curve and different technologies were tested, including Webex and Adobe Connect. Materials and activities related to the lecture series were uploaded to the VLE around the time of each event to offer a parallel and linked online learning journey.

In terms of teaching theories, due to the relatively recent novelty of food studies and food policy and their multidisciplinary character (Lang et al., 2009), the number of papers and books on the subject are still very limited but informative and innovative (Hilimire et al., 2014). The growing realisation by academics, civil society and policy makers of the interconnections amongst public health, nutrition, agriculture and environmental sustainability is giving way to an increasing interest in food; this popularity is also starting meta-thinking debates on how to best teach the complexity of cross-cutting and multidisciplinary food issues. Several scholars have written about the political elements intrinsic in the teaching of food studies (Francis et al., 2013) and the need to co-produce knowledge with other actors in the food system in order to achieve sustainability (e.g. recognising traditional knowledge of farmers) (Ison, 1990; Francis et al., 2013). IFSTAL encourages students to seek different perspectives, not just the loudest or dominant ones, and to study interconnections and push-pulls in the food system (Lang et al., 2009). This paper discusses the structure of the programme in year one and selected results of a survey to participants designed to collect data on their opinion about the different learning methods and channels used by IFSTAL. The last section of the paper discusses how these results were used to inform the new structure of the programme in Y2. 


\section{Methodology}

As part of the IFSTAL programme, a yearly survey is to be conducted of the participants. Other evaluation methods such as feedback forms after events and VLE metrics were also used to assess the success of the first iteration of the programme. Given the large size of the cohort, an online survey was considered however to be the most effective method to seek feedback in a consistent and efficient manner (Fricker and Schonlau, 2002). The first survey took place over May and June 2016 to evaluate students' experience of the initial year of the programme. Ethical approval was sought for the survey across all the participant institutions.

The survey questions were co-designed with educational coordinators at each of the affiliated institutions and a survey expert from the RVC team. The creation stages included meetings and a peer-review process as well as requesting a small sample of students to test the pilot survey using a likert scale. The questionnaire was composed of 23 questions structured in three sections: the past, present and future. The section on the past presented questions regarding students' views before joining IFSTAL, (e.g. motivations to join the programme). The present included questions regarding their current type and level of engagement with IFSTAL (what channels they valued the most). Finally, the section on the future focussed on asking students what other activities they would like to see taking place in IFSTAL Y2 in order to get their insights and empower them to act as co-designers and able to change the content and structure of the programme.

Taking advantage of RVC's business account, Survey Monkey was selected as the most convenient and appropriate platform to administer the survey. The invitation to complete the online survey was sent to all IFSTAL members via email communication. At the time the survey went live, 341 students had registered on the IFSTAL VLE and thus considered IFSTAL participants. Of that overall cohort, a smaller core of approximately 150 students was more actively engaged and regularly attending IFSTAL events. A response rate of one third of the cohort (115) was set as a target. A total of 57 students took part in the survey. Although the target was not reached, the response rate was considered positive as it represented an excellent proportion of the core cohort of highly engaged students who attended IFSTAL events regularly. The breakdown of respondents per institution was as follows: Warwick University (14), Reading University (13), City University of London (11), Oxford University (7) and LCIRAH (6) of which, London School of Hygiene and Tropical Medicine (2), Royal Veterinary College (2) and School of Oriental and African Studies (2). Six respondents preferred not to disclose their institution. The main limitation of this study is that it does not include an analysis of inter-factor relationships. Further research could include a deeper analysis of survey results and qualitative data from interviews with students. 
The next section discusses the main results from the survey and how the insights collected were used to inform the re-design of the programme for its second iteration.

\section{Discussion and conclusions: Integrating results into 2016/17 programme}

Due to space constraints, the summary of responses to two questions only is included in this paper (Table 1 and Table 2). Those two questions were selected for their relevance to the overall structure of the IFSTAL programme and the focus of this paper, but insights from other questions in the survey are also briefly discussed.

Overall, IFSTAL face to face activities were rated as "very useful" or "useful" by over $80 \%$ of respondents (Table 1). This seems to reflect how students value different ways of engaging with the IFSTAL community. The results indicated that students have a preference for interacting face to face over the VLE. The Away Day (the longest face to face activity carried out at the time the survey was administered since the first summer school that run for six days did not take place until July 2016) was by far the most valued activity. $26 \%$ of respondents reported finding the VLE not very user-friendly and difficult to $\log$ in, navigate and interact with others, while $58 \%$ thought it was easy to very easy. It was a surprise to the IFSTAL team how participants' profiles on the VLE were not considered as "very useful" by more students (c.15\%), given the fact they were designed to find peers in partners' institution sharing similar research interests. It would be interesting to carry out interviews with respondents to explore the reasons for this lack of engagement with profiles. 
Table 1. Summary of responses to Q11: How useful did you find the following aspects of IFSTAL?

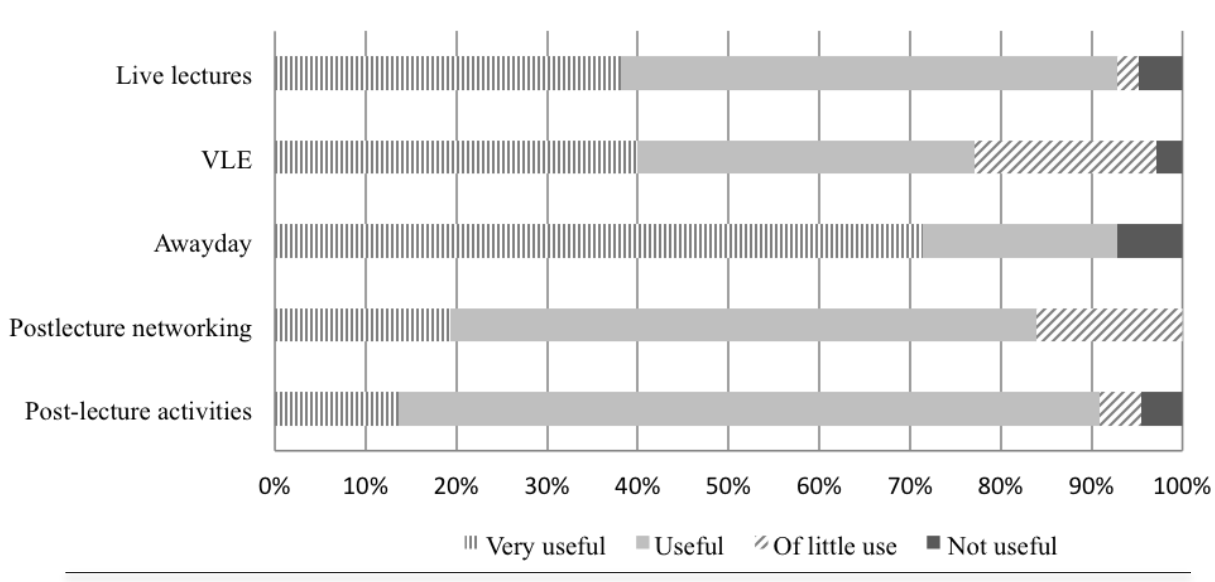

Source: IFSTAL Survey (2016)

Table 2. Summary of responses to Q17: How useful did have you found the online resources on the VLE (IFSTAL online learning platform)?

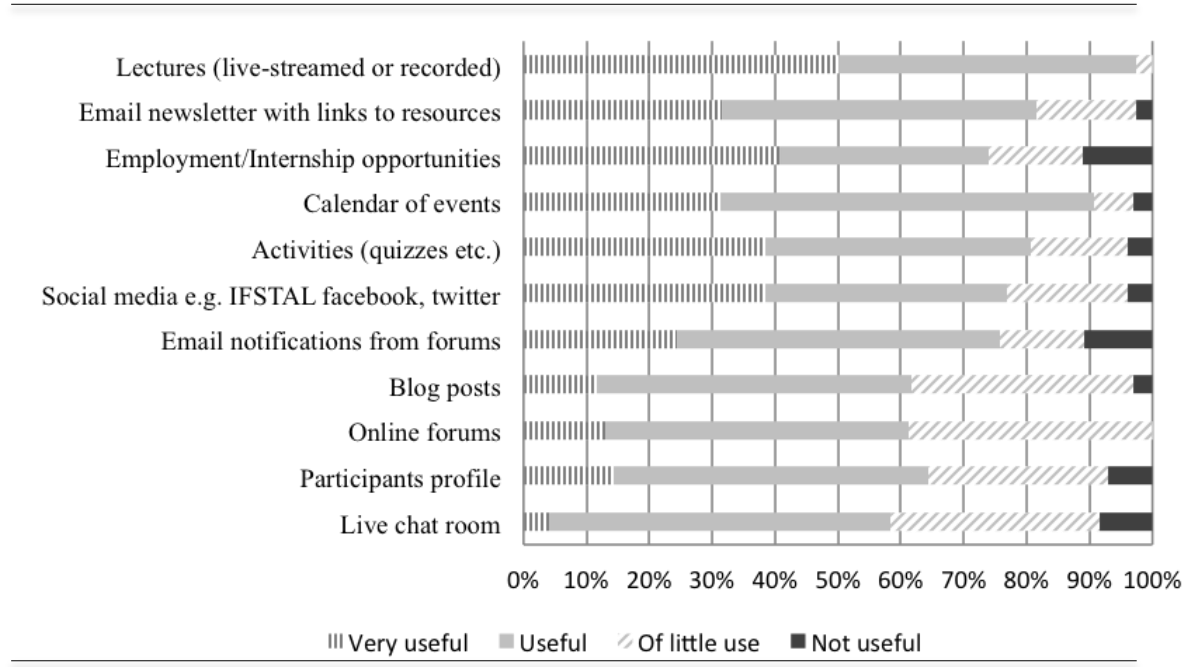

Source: IFSTAL Survey (2016) 
The voluntary character of the programme means the activities and content have to be engaging and balanced in terms of the time and effort required from students as some worry IFSTAL might clash with their paid programmes. While students really value the face-toface activities, it is difficult to foster engagement on the VLE since most of the theory and advice on increasing students' online participation and engagement on technology-enabled programmes focus on grading online participation as part of the grade policy (Deng and Tavares, 2013). An example of this point is when students are asked to post comments on a forum and reply to a couple of colleagues' comments in order to be awarded a certain percentage of their final mark on the module. IFSTAL is not able to play with the mark award as it is not an assessed programme. On the other hand, the voluntary aspect of the programme means that IFSTAL does not encounter restrictions from a regulatory body or from narrow assessment rules, allowing greater flexibility and room for experimentation.

Structural gamification strategies (Kapp et al., 2014) could be used further to motivate students, as IFSTAL is a non-credit bearing programme independent from their assessed programmes. With this in mind, more quizzes have been introduced in Y2 for students to self-assess their learning. However, some authors have recently shared their concerns about the use of gamification strategies such as badges, as they reward quantity over quality (Burt, 2016). Students also raised issues around lack of clarity about their progression and learning journey. Taking into account this point and students' preference for face to face activities, a flipped classroom approach was introduced in the Y2 programme (Berrett, 2012). The former lecture series was replaced by four online units released through the academic term. Materials and videos were made available online. Each unit was linked to a more interactive face to face workshop where students could apply their learning, ask questions and interact with peers and staff. Clearer programme objectives were prepared for Y2 alongside more specific student requirements listing what minimum level of engagement was expected from them. The VLE was redesigned to improve students' experience of their IFSTAL learning, including a more streamlined front page and content presented in smaller chunks (units), to allow greater flexibility.

More Away Days were planned for Y2 and the first ones were brought forward to the beginning of the academic year to offer students the opportunity to meet early and foster a sense of community, hopefully making students feel more at ease when contributing to the VLE. A student-only forum was created to offer students a protected and more private space, as some reported feeling intimidated by knowing over 300 users, including academics, would read their posts. The IFSTAL VLE offers students the chance to reflect more on how their contributions might be received by others with different views, which can foster deeper learning; the VLE also brings different IFSTAL participants together across sites, time and space (Siemens, 2004). Finally, another aspect of pedagogic theory relevant to IFSTAL is adult-learning theory or andragogy (Knowles, 1984). IFSTAL's 
diverse cohort is characterised for having a high proportion of mature and professional students. When designing activities, the use of the interdisciplinary character of the subject of study fostering multiple perspectives is a key lever to engage students and connect to their prior knowledge and professional experience (Lattuca et al. 2004). IFSTAL must continue to offer students a menu of activities and annotated reading lists so that students are able to deep in into the subject according to their wishes, time and previous experience, thus becoming proactive actors in stretching their own zone of proximal development (Vygotsky, 1978; Kilgore, 1999). This is also an attempt to encouraging the development of a responsible and independent approach to learning.

\section{References}

Ajates Gonzalez, R. \& Wells, R. (2016). Tackling Food Topics. BSA Network Magazine, March, 35-36.

Berrett, D. (2012). How 'flipping' the classroom can improve the traditional lecture. The chronicle of higher education, 12(2012): 1-14.

Burt, R. (2016). The Gamification of Education: No Badges Here. Available: http://www.theedublogger.com/2016/05/16/the-gamification-of-education-no-badgeshere/ [Last accessed: 3.6.16].

Cooner, T. S. (2011). Learning to create enquiry-based blended learning designs: Resources to develop interdisciplinary education. Social Work Education, 30(3), 312-330.

Deng, L. and Tavares, N. J. (2013). From Moodle to Facebook: Exploring students' motivation and experiences in online communities. Computers \& Education, 68:167176.

Francis, C., T. A., Breland, E. et al. (2013). Phenomenon-based learning in agroecology: A prerequisite for transdisciplinarity and responsible action. Agroecology and Sustainable Food Systems (37):60-75.;

Fricker, R. D. Jr., \& Schonlau, M. (2002). Advantages and disadvantages of internet research surveys: Evidence from the literature. Field Methods, 14(4), 347 